\title{
Violence within marriage among young people in Tamil Nadu
}

International Institute for Population Sciences (IIPS)

Population Council

Follow this and additional works at: https://knowledgecommons.popcouncil.org/departments_sbsr-pgy

Part of the Demography, Population, and Ecology Commons, Domestic and Intimate Partner Violence Commons, Family, Life Course, and Society Commons, Gender and Sexuality Commons, International Public Health Commons, and the Medicine and Health Commons How does access to this work benefit you? Let us know!

\section{Recommended Citation}

International Institute for Population Sciences (IIPS) and Population Council. 2009. "Violence within marriage among young people in Tamil Nadu," Youth in India: Situation and Needs Policy Brief no. 12. Mumbai: IIPS. 


\section{Violence within marriage among young people in Tamil Nadu}

\begin{abstract}
Introduction
Global attention on violence against women has increased significantly over the last decade. For example, the recent United Nations General Assembly resolution called upon member states to intensify their efforts to eliminate all forms of violence against women. ${ }^{a}$ In India too, policies and programmes have increasingly focused on preventing violence against women and supporting women who experience such violence. For example, the National Policy for the Empowerment of Women 2001 is committed to address all forms of violence against women at domestic and societal levels, including those arising from customs, traditions or accepted practices, with a view to eliminating its incidence. ${ }^{\mathrm{b}}$ Similarly, the Protection of Women from Domestic Violence Act, 2005 provides for immediate and long-term relief to women in situations of violence of any kind in the home. ${ }^{\mathrm{c}}$
\end{abstract}

While several studies in India have highlighted the widespread prevalence of physical and sexual violence within marriage, little is known about violence within marriage among young people and the health consequences of these experiences for young women. This policy brief documents the perceptions of married young people in Tamil Nadu on wife beating, the magnitude of violence within marriage among them and the associations between such experiences and adverse health outcomes for young women, and argues that sexual and reproductive health programmes must address violence within marriage as a matter of rights and health.

\section{The study}

The Youth in India: Situation and Needs study is a sub-nationally representative study undertaken for the first time in India of key transitions experienced by young people in six states of India, including Tamil Nadu. The study included a representative survey of young people in both rural and urban settings. Respondents included unmarried women and men and married women aged 15-24 and, in view of the paucity of married men in these ages, married men aged 15-29.

In Tamil Nadu, the survey was conducted in 2006-07. A total of 7,996 married and unmarried young women and men were interviewed in the survey. These included 1,322 married young men, 1,666 unmarried young men, 2,007 married young women and 3,001 unmarried young women. This brief is based on findings obtained from married youth.

The majority of young people believe that wife beating is justified

The majority of married youth- $51 \%$ of young men and $60 \%$ of young women-justified wife beating in at least one of the four situations explored in the survey. ${ }^{1}$ Young men and women were most likely to perceive that wife beating was

Percentage of married young men and women who belived wife beating is justified in selected situations

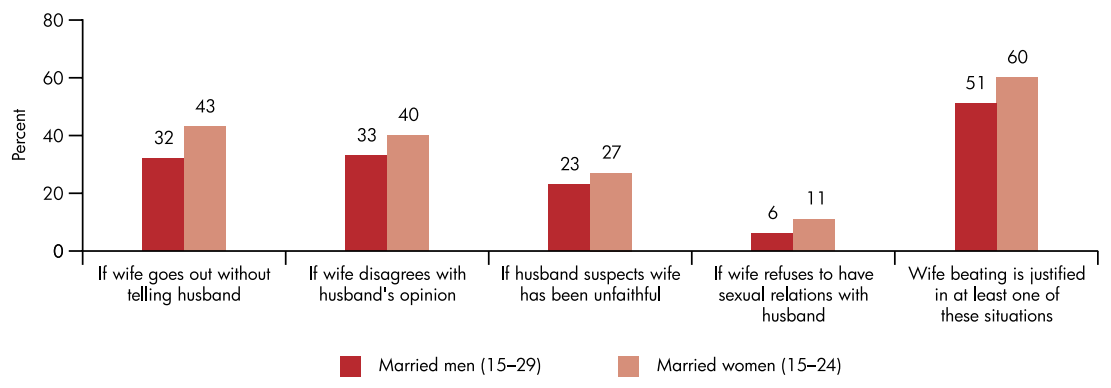

a United Nation. 2006. UN general assembly resolution 61/143 of 19th December, 2006.

b Ministry of Women and Child Development (MOWCD). 2001. National Policy for the Empowerment of Women. New Delhi: Government of India.

${ }^{c}$ Ministry of Women and Child Development (MOWCD). 2006. Protection of Women from Domestic Violence Act (2005). The Gazette of India (Extraordinary). Part II, Section 3, Sub-section (ii). MOWCD. Government of India.

${ }^{1}$ The four situations explored in the survey included if a woman went out without telling her husband, if a woman disagreed with her husband's opinion, if a woman's husband suspected her of being unfaithful and if a woman refused to have sex with her husband. 
justified if a woman went out without telling her husband or if she disagreed with her husband's opinion.

Violence within marriage is common among young people

Youth Study findings highlight that violence within marriage was common among young people. More than one in four young women reported that they had ever experienced physical violence perpetrated by their husband and an even larger percentage of young men (34\%) reported having perpetrated physical violence on their wife. Married young women living in rural settings were more likely than their urban counterparts to report the experience of physical violence within marriage. Similarly, young men in rural areas were somewhat more likely than their urban counterparts to report the perpetration of physical violence on their wife.

The experience of physical violence within marriage began early for a considerable proportion of women; one in eight young women reported that they had experienced physical violence within a year of marriage, and one in five young men reported that they had perpetrated physical violence on their wife within the first year of marriage.

The experience of recent physical violence, that is, in the 12 months preceding the interview, was reported by one-fourth of young women and the perpetration of recent physical violence was reported by almost one-third of young men (31\%).

Extent of physical violence within marriage experienced by young women (women's reports)

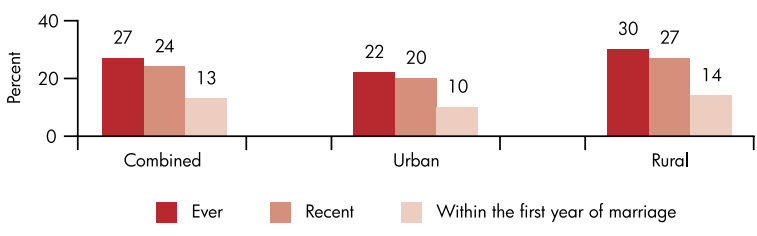

Extent of physical violence perpetrated by husbands within marriage (men's reports)

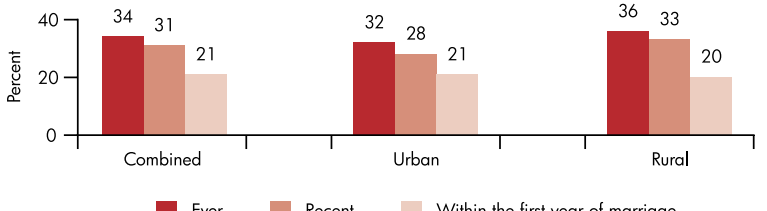

Findings also show that one in four young women had been forced to engage in sex by their husband in the course of married life. Fewer young men $(15 \%)$, in comparison, reported having ever perpetrated sexual violence on their wife. Unlike in the case of physical violence, rural young women were about as likely as urban young women to have ever experienced sexual violence within marriage, and likewise, rural young men were as likely as urban young men to have ever perpetrated sexual violence within marriage.

For considerable proportions of young women, forced sex occurred at sexual initiation itself; one-fifth of young women reported that the first sexual experience within marriage had been forced. Recent experience of sexual violence was reported by one in seven young women; just $4 \%$ of young men, in comparison, reported having perpetrated sexual violence in the 12 months preceding the interview.

Extent of sexual violence within marriage experienced by young women (women's reports)

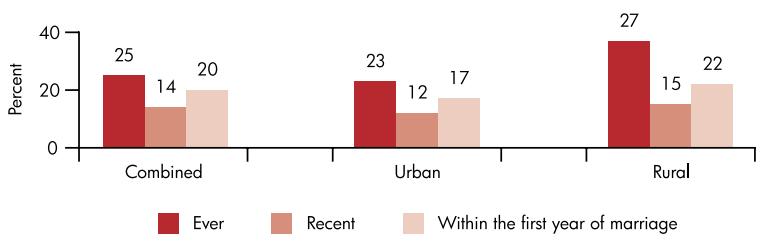

Extent of sexual violence within marriage perpetrated by young men (men's reports)

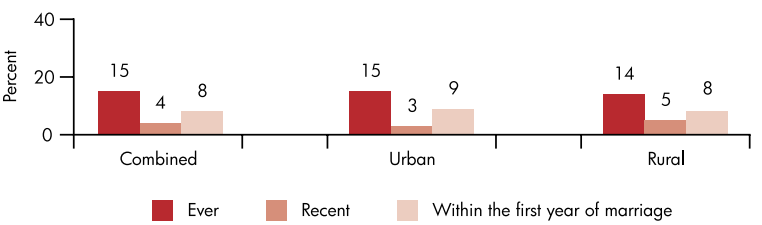

Educationally and economically disadvantaged women are particularly vulnerable to violence within marriage

Findings suggest that less educated young women were more at risk of experiencing violence within marriage than were their more educated counterparts. For example, 37\% of young women with no education, compared to $16 \%$ of those with 12 or more years of schooling, reported having ever experienced physical violence within marriage. Similarly, $30 \%$ of young women with no education, compared to $20 \%$ of those with 12 or more years of schooling, reported having ever experienced sexual violence within marriage.

Among young men too, the less educated were more likely than the more educated to have perpetrated physical violence on their wife; $47 \%$ of young men with no education compared to $19 \%$ of those with 12 or more years of schooling reported having perpetrated physical violence within marriage. However, less educated young men were only mildly more likely than the more educated to have perpetrated sexual violence within marriage. 


\section{POLICY BRIEF Violence within marriage among young people in Tamil Nadu}

Extent of physical and sexual violence experienced by young women by years of schooling and household economic status

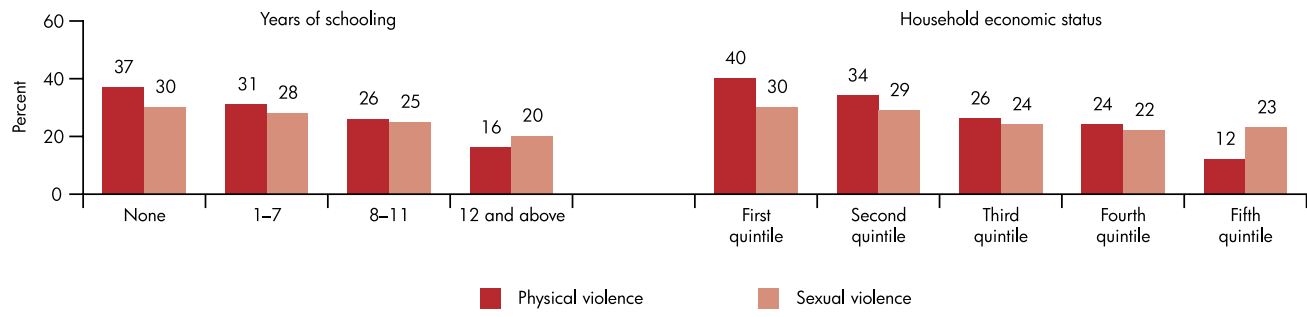

Extent of physical and sexual violence perpetrated by young men by years of schooling and household economic status

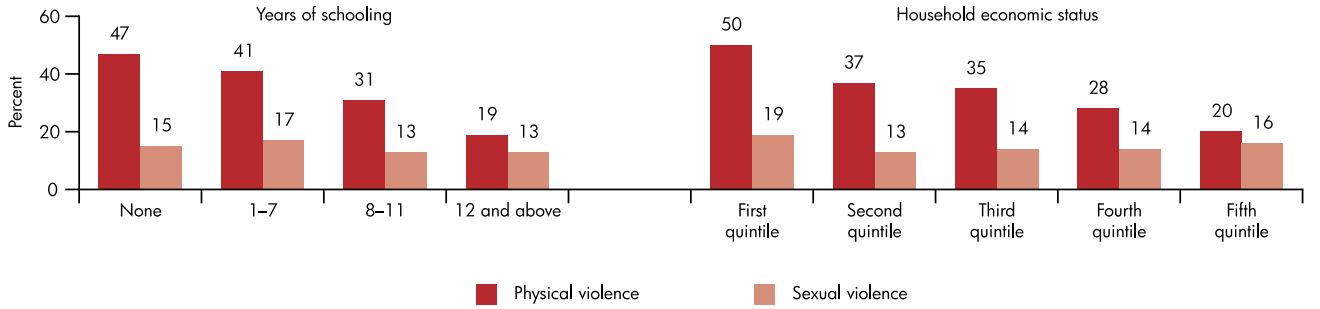

Findings also suggest an inverse association between young women's household economic status, as measured by wealth quintiles (with the first quintile representing households of the lowest wealth status and the fifth quintile representing households with the highest wealth status), and experience of violence within marriage. For example, experience of physical violence within marriage fell from $40 \%$ among young women in the poorest quintile to $12 \%$ among those in the wealthiest quintile. Similarly, experience of sexual violence within marriage declined from $30 \%$ among those in the poorest quintile to $23 \%$ among those in the wealthiest quintile.

Young men belonging to the poorest quintile were more likely than those belonging to the wealthiest quintile to have perpetrated physical violence on their wife, and were about as likely to have perpetrated sexual violence on their wife.
Violence within marriage is closely associated with adverse health outcomes for women

Findings highlight that women who suffer physical or sexual violence within marriage are considerably more likely than other women to experience a number of adverse health outcomes, even after controlling for such background variables as age, education, working status, rural-urban residence, and economic status of family.

For example, young women who had experienced physical violence were more likely than those who had not to report symptoms of genital infection: $28 \%$ of young women who had experienced physical violence, compared to $22 \%$ of those who had not, reported symptoms of genital infections in the three months preceding the interview. Women who had experienced sexual violence, in contrast, were just mildly more likely than those who had not to experience symptoms of genital infection.

Association between violence within marriage and health outcomes*

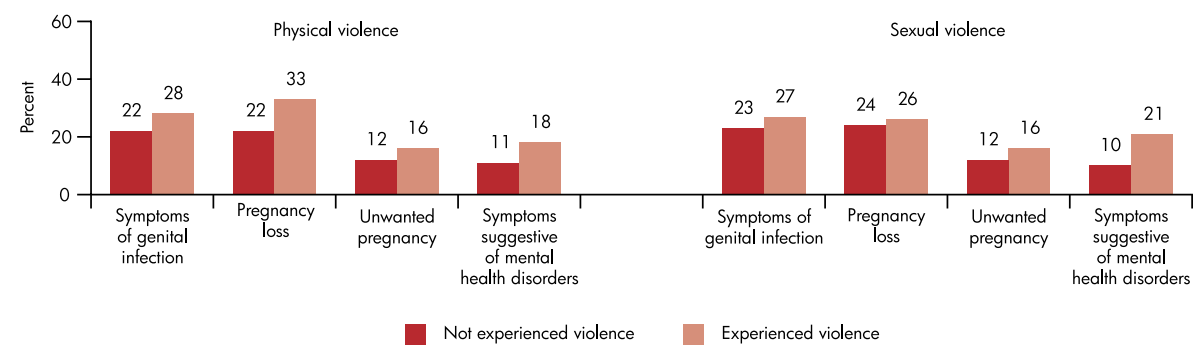

* controlling for the effects of such background factors as age, education, working status, rural-urban residence and household economic status 
Physical violence was also associated with the experience of pregnancy loss; among young women who had ever been pregnant, $33 \%$ of young women who had experienced physical violence compared to $22 \%$ of those who had not reported at least one miscarriage, abortion or still-birth. Sexual violence, in contrast, appeared to be unrelated with the experience of pregnancy loss.

Both physical and sexual violence appeared to be linked with unwanted pregnancy; among young women who had ever been pregnant, $16 \%$ of young women who had experienced physical violence compared to $12 \%$ of those who had not reported that their last pregnancy was mistimed or unwanted. Similar differences were observed in the case of sexual violence as well.

Findings also suggest that the experience of physical and sexual violence was positively correlated with the experience of symptoms or behaviours suggestive of mental health disorders. For example, young women who had experienced physical violence were more likely than those who had not to report 3 or more symptoms suggestive of mental health disorders in the one month preceding the interview ( $18 \%$ versus $11 \%)$. The corresponding percentages among those who had experienced sexual violence and those who had not were 21 and 10 , respectively.

\section{Programme recommendations}

Findings underscore the need for multi-sectoral efforts to prevent violence within marriage among young people and to support young women who experience such violence.

\section{Build new models of masculinity and femininity}

Programmatic efforts are needed that enable young people to recognize the rights of women within marriage, that build agency among young women, that enable better communication among young couples and that build new models of masculinity and femininity. Such programmes should focus not only the married but also the about-to-be married.

Enforce existing laws on the protection of women from domestic violence It is important to ensure greater commitment on the part of law enforcement agencies to enforce existing laws on the protection of women from domestic violence. Also required are efforts to raise awareness about legal provisions of the law among young people, their families and their communities more generally.

Engage influential adults in young people's lives

Equally important are programmes that sensitize influential adults, including parents, parents-in-law and community gate-keepers more generally about the distinct vulnerability of married young women to both physical and sexual violence, the adverse health consequences of violence and ways in which they may support young people to develop egalitarian marital relationship.

\section{Help identify and support women experiencing violence}

Findings call for services for women experiencing violence. Sexual and reproductive health programmes must recognize the linkages between the experience of physical and sexual violence and sexual and reproductive health outcomes. Indeed, many clients of sexual and reproductive health services experience physical and sexual violence within marriage, and this inhibits, for example, their ability to protect themselves from infections and go through pregnancy safely. Measures need to be in place that screen women presenting for general health or reproductive health services for the experience of physical and sexual violence within marriage. Such programmes must incorporate education and counseling services to help prevent violence within marriage and address its adverse effects on sexual and reproductive health.

For additional information on the study, please send an e-mail to iipsyouth@rediffmail.com or info-india@popcouncil.org 